\title{
On Behavioral Response of Microstructural Slip on the Development of Magnetohydrodynamic Micropolar Boundary Layer Flow
}

\author{
Raja Mehmood Khan, ${ }^{1,2}$ Waqas Ashraf, ${ }^{2}$ Muhammad Sohail (D), ${ }^{2}$ Shao-Wen Yao (D), \\ and Wael Al-Kouz (iD ${ }^{4}$ \\ ${ }^{1}$ Department of Mathematics, HIT Degree College Taxila Cantt, Taxila 47070, Pakistan \\ ${ }^{2}$ Department of Applied Mathematics and Statistics, Institute of Space Technology, Islamabad 44000, Pakistan \\ ${ }^{3}$ School of Mathematics and Information Science, Henan Polytechnic University, Jiaozuo 454000, China \\ ${ }^{4}$ Mechanical and Maintenance Engineering Department, German Jordanian University, Amman, Jordan
}

Correspondence should be addressed to Shao-Wen Yao; yaoshaowen@hpu.edu.cn

Received 15 September 2020; Revised 27 September 2020; Accepted 15 October 2020; Published 3 November 2020

Academic Editor: Mostafa M. A. Khater

Copyright (C) 2020 Raja Mehmood Khan et al. This is an open access article distributed under the Creative Commons Attribution License, which permits unrestricted use, distribution, and reproduction in any medium, provided the original work is properly cited.

\begin{abstract}
In this paper, the concept of microstructural slip is introduced in the flow of micropolar fluids pertinent to model various physical situations. The flow is modeled by a set of PDEs which are transformed to a nonlinear system of ODEs by employing boundary layer transformations. The system of governing equations is implemented using MATLAB bvp4c function along with the initialboundary conditions. The code is validated by comparing the computed results in the limiting case with the available literature. Influence of microstructural slip on the skin friction coefficient and Nusselt number along with hydrodynamic and thermal boundary layer profiles is studied and discussed. It is found that, in the presence of microstructural slip, the microrotational velocity boundary layer thickness decreases up to a maximum of $37.5 \%$ in its value, in comparison to the case where there is no microstructural slip effect. The results predict that, in the presence of first-order translational slip, the microrotations have shown counterrotational phenomena in comparison to the case where there is no translational slip effect. Moreover, second-order translational slip results in declining the microrotational velocity and associated layer thickness.
\end{abstract}

\section{Introduction}

It is worth mentioning that the present slip model contains a true description of slip velocity at the wall in the content of micropolar flow. Translational slip effects have been studied in the literature in a number of physical situations pertinent to different modeling aspects. For instance, reduction in friction, energy conversation, and mimicking biological water channels [1]. The literature survey reveals significant interest in analyzing the slip effects in various geometries for several fluids [2, 3]. Micropolar fluids [4] are a class of polar fluids [5] with microstructure [6]. These fluids are pertinent to model various physical situations [7] and are important to study for many industrial applications [8], for instance, paper and fiberglass production, extrusion of plastic sheets in the aerodynamical study, polymer processes, and extraction of oil. A detailed review, on the theory and applications of micropolar fluids, was given by Crane [9]. $\mathrm{He}$ worked initially on steady, boundary layer flow of an incompressible viscous fluid over a linearly stretching sheet. Heat and mass transfer with suction and blowing was analyzed by Gupta and Gupta [10].

A familiar article of all the aforementioned studies replicated the no-slip boundary condition. However, there may be natural situations where the no-slip boundary condition may not be relevant. The slip flow boundary condition was first introduced by C. L. M. H. Navier more than a century ago. In microsystems, slip 
flows show a most important task, for instance, hard disk drive, micropumps, nozzles, and microvalves. He and Cai [11] observed the combined impact of temperature jump and velocity slip on a boundary layer flow towards a flat plate. The influence of velocity slip and temperature jump on a boundary layer flow of MHD pseudoplastic power law fluid over a moving permeable surface was considered by Xinnui et al. [12]. Unsteady boundary layer flow towards a stretching permeable surface was presented by Hosseini et al. [13]. They analyzed that, with rise in thermal and jump parameters, the skin friction coefficient and heat transfer rates diminish. Farhan at al. [14] proposed a single-step implicit block method which is quite suitable for solving nonlinear stiff ordinary differential equations. The proposed algorithm is zero stable and convergent. They investigated the flow numerically and concluded the results for temperature jump and velocity slip. Daniel et al. [15] discussed MHD boundary layer flow of a nanofluid towards a porous sheet for convective boundary condition along with slip effect. Mebarek-Oudina et al. [16] discussed a numerical approach finite volume method via computer code with Fortran programming to improve the phenomena of heat transfer by investigating MHD natural convection in porous cylindrical annulus filled with magnetized nanomaterial. The top and bottom walls are thermally insulated, outer wall at lesser temperature. Mostafa and Shimaa [17] gave the analysis of flow and heat transfer characteristics of magnetohydrodynamics mixed convection flow of a micropolar fluid past a stretching sheet with slip velocity at the surface and heat generation (absorption). Mahmood et al. [18] used the spectral homotopy analysis method (SHAM) for the solution of heat transfer phenomena in megnetohydrodynamic (MHD) Jeffery-Hamel flow. The two-dimensional viscous incompressible flow is taken into account for both convergent and divergent channels. In their study, a strong agreement of results is shown in comparison with shooting and the differential transform method (DTM). Mukhopadhyay [19] discussed the velocity slip and thermal slip over MHD boundary layer flow and heat transfer towards a porous exponential stretching sheet in presence of a magnetic field. Ali et al. [20] used a modified implicit finite difference scheme for the solution of twodimensional fractional subdiffusion equation. They carried out the stability and convergence of the proposed scheme and found that the scheme is unconditionally stable, and approximate solution converges to the exact solution. Sohail et al. [21] explored theoretically and numerically heat and mass transfer with irreversibility for the flow of couple stressed fluid passing through a nonlinear stretched surface. A useful discussion is focused for variable thermophysical characteristics in their proposed model. Ali at al. [22-24] explored a new numerical approach, implicit difference scheme, for the variable-order fractional Riemann-Liouville Integral formula for the fractional subdiffusion equation. The one-dimensional time-fractional wave-diffusion equation is also resolved by the abovementioned scheme. They also discovered a new forth-order implicit difference scheme and used it to solve the two-dimensional timefractional modified subdiffusion equation. The effectiveness, unconditional stability, convergence, and consistency of the proposed scheme are analyzed by comparing the results using the von Neumann method. Abdelsalam and Sohail [25] described theoretically the heat and mass transfer phenomena of a three-dimensional viscous fluid flow over a nonlinear stretched surface. Optimal homotopic procedure is used to resolve nonlinear system of ordinary differential equations. Several references in this field can be found in [26-28]. The results are compared with the publish work, and excellent agreement is found.

The literature discussed above only uses the theory of classical continuum to describe the slip velocity. Although the nonclassical continuum (i.e., micropolar theory) is used by many researchers in the literature, they defined the slip velocity with only the translational degree of freedom (i.e., the translational velocity). Here, for the first time in the literature, the effect rotational degree of freedom has been introduced simply through the kinematic relation in the description of velocity slip based on the fact that the shear stress takes the contribution also from the rotational degree of freedom of the fluid particles. The definition of velocity slip is modified, thereby incorporating the complete description of the micropolar continuum. Moreover, the effects of rotational slip velocity on some physical parameters are shown and discussed. These results are compatible with the actual physical assumptions in the theory which reveals the importance of the research study.

The rest of the paper is organized as follows: in Section 2, microstructural slip (translational and rotational slip) flow conditions are shown along with the flow governing equations. In Section 3, solution methodology is given. In Section 4, the results are shown and discussion is presented. Finally, conclusions are drawn in Section 5.

\section{Mathematical Formulation}

In this section, we describe the microstructural slip flow boundary conditions along with the flow governing equations. The flow equations are defined as

$$
\begin{gathered}
\frac{\partial u}{\partial x}+\frac{\partial u}{\partial y}=0 \\
u \frac{\partial u}{\partial x}+v \frac{\partial u}{\partial y}=\frac{(\mu+\kappa)}{\rho} \frac{\partial^{2} u}{\partial y^{2}}+\frac{\kappa}{\rho} \frac{\partial N}{\partial y}-\frac{\sigma B_{0}^{2}}{\rho} u \\
u \frac{\partial N}{\partial x}+v \frac{\partial N}{\partial y}=\frac{\Omega}{\rho j} \frac{\partial^{2} N}{\partial y^{2}}-\frac{\kappa}{\rho j}\left(2 N+\frac{\partial u}{\partial y}\right), \\
u \frac{\partial T}{\partial x}+v \frac{\partial T}{\partial y}=\frac{\kappa}{\rho c_{p}} \frac{\partial^{2} T}{\partial y^{2}}-\frac{1}{\rho c_{p}} \frac{\partial q_{r}}{\partial y} .
\end{gathered}
$$

The boundary conditions are 


$$
\begin{aligned}
& u=u_{w}+U_{\text {slip }}, \\
& v=0, \\
& N=-n \frac{\partial u}{\partial y}, \\
& T=T_{w}, \text { at } \\
& y=0, \\
& u \longrightarrow 0, \\
& N \longrightarrow 0, \\
& T \longrightarrow T_{\infty}, \text { as }
\end{aligned}
$$

where $U_{\text {slip }}$ is the slip velocity at the surface, the modified form of micropolar kinematics is given as

$$
\begin{aligned}
& U_{\text {slip }}=\frac{2}{3}\left(\frac{3-\alpha l^{2}}{\alpha}-\frac{3}{2} \frac{1-l^{2}}{\kappa_{n}}\right) \lambda \frac{\partial u}{\partial y}-\frac{1}{4}\left[l^{4}+\frac{2}{\kappa_{n}^{2}}\left(1-l^{2}\right)\right] \lambda^{2} \frac{\partial}{\partial y}\left(\frac{\partial u}{\partial y}-r_{0} N\right), \\
& U_{\text {slip }}=A \frac{\partial u}{\partial y}+B \frac{\partial}{\partial y}\left(\frac{\partial u}{\partial y}-r_{0} N\right) .
\end{aligned}
$$

Let us define a similarity variable by

$$
\xi=\sqrt{\frac{a}{v}} y .
$$

The dimensionless variables $f, \theta$, and $g$ are defined as

$$
\begin{aligned}
& f(\xi)=\frac{\psi}{\sqrt{a v x}}, \\
& g(\xi)=\frac{N}{a x \sqrt{a / \nu}}, \\
& \theta(\xi)=\frac{T-T_{\infty}}{T_{w}-T_{\infty}} .
\end{aligned}
$$

The equation of continuity is satisfied if we choose stream function $\psi(x, y)$ such that

$$
\begin{aligned}
& u=\frac{\partial \psi}{\partial x}, \\
& v=-\frac{\partial \psi}{\partial y} .
\end{aligned}
$$

Using dimensionless variables and similarity transformation, equations (1)-(4) are reduced into the ODEs as follows:

$$
(1+\beta) f^{\prime \prime \prime}=f^{\prime 2}-f f^{\prime \prime}-\beta g^{\prime}+M f^{\prime},
$$

$$
\left(1+\frac{\beta}{2}\right) g^{\prime \prime}=\beta\left(2 g+f^{\prime \prime}\right)-f g^{\prime}+f^{\prime} g
$$

$$
\left(\frac{3 R+4}{3 R}\right) \theta^{\prime \prime}=-\operatorname{Pr} f \theta^{\prime},
$$

with boundary conditions,

$$
\begin{aligned}
f(0) & =0, \\
f^{\prime}(0) & =1+\gamma f^{\prime \prime}(0)+\delta f^{\prime \prime \prime}(0)+r_{0} g^{\prime}(0), \\
g(0) & =-n f^{\prime \prime}(0), \\
\theta(0) & =1, \text { at } \\
\xi & =0 \\
f^{\prime}(\infty) & \longrightarrow 0, \\
g(\infty) & \longrightarrow 0, \\
\theta(\infty) & \longrightarrow 0, \text { as } \\
\xi & \longrightarrow \infty,
\end{aligned}
$$

where the governing parameters are defined by 
TABle 1: Comparison of skin friction coefficient $-f^{\prime \prime}(0)$ with slip factor $\gamma$, when $M=\delta=r_{0}=0.0$.

\begin{tabular}{lccr}
\hline$\gamma$ & Present result & Wubshet $^{25}$ & Sahoo $^{21}$ \\
\hline 0.0 & 1.0000 & 1.000000 & 1.001154 \\
0.1 & 0.8719 & 0.872082 & 0.871447 \\
0.2 & 0.7762 & 0.776377 & 0.774933 \\
0.3 & 0.7014 & 0.701548 & 0.699738 \\
0.5 & 0.5911 & 0.591196 & 0.589195 \\
1.0 & 0.4301 & 0.430160 & 0.428450 \\
2.0 & 0.2840 & 0.283980 & 0.282893 \\
3.0 & 0.2140 & 0.214055 & 0.213314 \\
5.0 & 0.1448 & 0.144841 & 0.144430 \\
10 & 0.0812 & 0.081243 & 0.081091 \\
20 & 0.0438 & 0.043790 & 0.043748 \\
\hline
\end{tabular}

$$
\begin{aligned}
\operatorname{Pr} & =\frac{\nu}{A}, \\
M & =\frac{\sigma B_{0}^{2}}{\rho a}, \\
\beta & =\frac{\kappa}{\mu} .
\end{aligned}
$$

Skin friction coefficient and Nusselt number are defined as

$$
\begin{aligned}
C_{f} & =\frac{\tau_{w}}{\rho u_{w}^{2}}, \\
N u_{x} & =\frac{x q_{w}}{k\left(T_{w}-T_{\infty}\right)},
\end{aligned}
$$

where the wall shear stress $\tau_{w}$ and wall heat flux $q_{w}$ are given by

$$
\begin{aligned}
& \tau_{w}=\left[(\mu+\kappa) \frac{\partial u}{\partial y}+\kappa N\right]_{y=0}, \\
& q_{w}=-\kappa\left(\frac{\partial T}{\partial y}\right)_{y=0} .
\end{aligned}
$$

By using equation (16) in equation (15), one can arrive at

$$
\begin{aligned}
C_{f} \sqrt{\operatorname{Re}_{x}} & =-(1+\beta(1-n)) f^{\prime \prime}(0), \\
\frac{N u_{x}}{\sqrt{\operatorname{Re}_{x}}} & =-\theta^{\prime}(0),
\end{aligned}
$$

where $\operatorname{Re}_{x}=a x^{2} / \nu$ and $N u_{x}$ are local Reynolds and local Nusselt numbers, respectively.

\section{Solution Methodology and Code Validation}

To solve numerically the coupled set of ordinary differential equations (ODEs) in equations (10)-(12) subjected to the boundary conditions in equation (13), we use bvp4c function in MATLAB. For this purpose, the function is modified according to equations (10)-(12) and the boundary conditions in equation (13) are implemented. To validate the implemented code, the physical parameters, i.e., the skin friction coefficient and the Nusselt numbers, are calculated for different values of parameters. These results are compared with the results obtained by Wubshet ${ }^{25}$ in the case of translational slip velocity, and a good agreement is found. In this respect, Tables 1-4 are presented as follows.

In Table 1, slip factor $\gamma$ results in declining the skin friction coefficient which is compatible with the other research studies $[29,30]$.

In Table 2, heat transfer coefficient is comparatively analyzed numerically.

In Table 3, skin friction coefficient is numerically studied and comparison of results is shown. It depicts that skin friction increases with magnetic number, whereas opposite trend is observed for material parameter. When secondorder slip parameter is reduced, the skin friction behaves alike.

In Table 4, the local Nusselt number is numerically examined and the results are compared with Wubshet ${ }^{28}$. It is seen that local Nusselt number decreases with magnetic number, whereas opposite trend is experienced for material parameter. When second-order slip parameter is lessened, the Nusselt number also shows a behavior like slip parameter.

\section{Results and Discussion}

In this section, the effect of microstructural slip on the development of microrotation velocity, macroscopic velocity, and temperature boundary layer profiles is shown through tables and graphs and discussion is presented in detail. Moreover, the influence of microstructural slip on the skin friction coefficient and Nusselt number is analyzed. In Table 5, these physical parameters are calculated and shown with varying values of the rotational and translational velocity slip factors. It is found that, with the increase in rotational and translational slip parameters, the values of the skin friction coefficient decrease. Moreover, the values of Nusselt number increase with the increase in the translational and rotational slip parameters. This finding is in accordance with the observation of Wubshet ${ }^{25}$, where only the effect of translational slip parameter is shown.

In Figure 1, the development of microrotational velocity boundary layer is depicted with varying microstructural slip for three different cases. In the first case, the perimeter $n(0 \leq n \leq 1)$ is associated with the concentration factor; the rotation of the microelements near the stretching sheet is 
TABle 2: Numerical comparison of values of local Nusselt number $-\theta^{\prime}(0)$ for different values of $\operatorname{Pr}$ when $M=\beta=0.0$ and $n=0.5$

\begin{tabular}{lccc}
\hline Pr & Ishak $^{24}$ & ${\text { Present result } r_{0}=0,1}$ & Wubshet \\
\hline 0.72 & 0.4631 & 0.4623 & 0.4636 \\
1.0 & 0.5820 & 0.5809 & 0.5822 \\
3.0 & 1.1652 & 1.1634 & 1.1652 \\
10.0 & 2.3080 & 2.3047 & 2.3080 \\
100.0 & 7.7657 & 7.7552 & 7.7657 \\
\hline
\end{tabular}

TABLe 3: Numerically computed values of skin friction coefficient $-f^{\prime \prime}(0)$ when $\operatorname{Pr}=1$ and $n=0.5$ for different values of.M, $\beta$, and $\delta$.

\begin{tabular}{|c|c|c|c|c|c|c|c|c|}
\hline \multirow[t]{2}{*}{$M$} & \multirow[t]{2}{*}{$\beta$} & \multirow[t]{2}{*}{$\delta$} & \multicolumn{3}{|c|}{$\begin{array}{c}-f^{\prime \prime}(0) \\
\text { Wubshet }^{25}\end{array}$} & \multicolumn{3}{|c|}{$\begin{array}{c}-f^{\prime \prime}(0) \\
\text { Present results }\end{array}$} \\
\hline & & & $\gamma=1$ & $\gamma=2$ & $\gamma=3$ & $\gamma=1$ & $\gamma=2$ & $\gamma=3$ \\
\hline 0.1 & 0.1 & -1 & 0.3220 & 0.2399 & 0.1914 & 0.3219 & 0.2398 & 0.1913 \\
\hline 0.2 & 0.1 & -1 & 0.3262 & 0.2434 & 0.1943 & 0.3262 & 0.2433 & 0.1942 \\
\hline 0.3 & 0.1 & -1 & 0.3293 & 0.2459 & 0.1964 & 0.3293 & 0.2459 & 0.1964 \\
\hline 0.4 & 0.1 & -1 & 0.3315 & 0.2478 & 0.1979 & 0.3315 & 0.2478 & 0.1979 \\
\hline 0.2 & 1 & -1 & 0.3173 & 0.2371 & 0.1896 & 0.3172 & 0.2370 & 0.1895 \\
\hline 0.2 & 2 & -1 & 0.3068 & 0.2301 & 0.1846 & 0.3066 & 0.2300 & 0.1845 \\
\hline 0.2 & 3 & -1 & 0.2971 & 0.2239 & 0.1802 & 0.2967 & 0.2236 & 0.1800 \\
\hline 0.2 & 4 & -1 & 0.2884 & 0.2183 & 0.1763 & 0.2878 & 0.2179 & 0.1759 \\
\hline 0.2 & 2 & -1 & 0.3068 & 0.2301 & 0.1846 & 0.3066 & 0.2300 & 0.1845 \\
\hline 0.2 & 2 & -2 & 0.2588 & 0.2039 & 0.1683 & 0.2586 & 0.2037 & 0.1681 \\
\hline 0.2 & 2 & -3 & 0.2262 & 0.1841 & 0.1551 & 0.2259 & 0.1839 & 0.1549 \\
\hline
\end{tabular}

chosen to be zero, thereby implying the strong concentration [31]. In the second and third cases, $n=0.5$ and $n=1$ are chosen, respectively, thereby implying the weak concentration [32]. It is observed that, in the case of strong concentration, where $n=0$, the thickness of microrotational velocity boundary layer increases with increasing the value of microstructural slip. However, in the case of weak concentration of the rotation of microelements near the stretching surface, the thickness of microrotational velocity boundary layer decreases with increasing the value of microstructural slip.

In Figure 2, the development of microstructural boundary layer profiles near the stretching surface is studied in the presence and absence of magnetic field effect. It is observed that microstructural slip affects the microrotational boundary layer profiles significantly in the presence of magnetic field effect in comparison to the absence of magnetic field effect. Moreover, the microrotational boundary layer profiles decrease in both the cases with increase in microstructural slip.

In Figures 3 and 4, microstructural slip effects on the development of microrotational velocity boundary layer profiles are predicted. Here, an interesting feature of microstructural slip is observed which is that the thickness of microrotational boundary layer profiles is bounded to variation of microstructural slip. We observe that, in the presence of microstructural slip, the microrotational velocity boundary layer thickness decreases up to a maximum of $37.5 \%$ in its value, in comparison to the case where there is no microstructural slip effect. Moreover, in a flow situation, microstructural slip effects are bounded to increasing microstructural slip.
TABle 4: Computed values of local Nusselt number $-\theta^{\prime}(0)$ when $\operatorname{Pr}=1$ and $n=0.5$ for different values of $M, \beta$, and $\delta$.

\begin{tabular}{cccccccccc}
\hline & \multicolumn{4}{c}{$-\theta^{\prime}(0)$} & \multicolumn{3}{c}{$-\theta^{\prime}(0)$} \\
$M$ & $\beta$ & $\delta$ & \multicolumn{3}{c}{ Wubshet $^{25}$} & \multicolumn{3}{c}{ Present results } \\
& & & $\gamma=1$ & $\gamma=2$ & $\gamma=3$ & $\gamma=1$ & $\gamma=2$ & $\gamma=3$ \\
\hline 0.1 & 0.1 & -1 & 0.3816 & 0.3432 & 0.3167 & 0.3773 & 0.3370 & 0.3085 \\
0.2 & 0.1 & -1 & 0.3603 & 0.3214 & 0.2947 & 0.3540 & 0.3122 & 0.2825 \\
0.3 & 0.1 & -1 & 0.3411 & 0.3024 & 0.2761 & 0.3327 & 0.2900 & 0.2599 \\
0.4 & 0.1 & -1 & 0.3239 & 0.2859 & 0.2605 & 0.3130 & 0.2702 & 0.2404 \\
0.2 & 1 & -1 & 0.4066 & 0.3623 & 0.3315 & 0.4038 & 0.3579 & 0.3252 \\
0.2 & 2 & -1 & 0.4431 & 0.3954 & 0.3620 & 0.4418 & 0.3934 & 0.3590 \\
0.2 & 3 & -1 & 0.4703 & 0.4206 & 0.3856 & 0.4698 & 0.4199 & 0.3844 \\
0.2 & 4 & -1 & 0.4915 & 0.4407 & 0.4046 & 0.4915 & 0.4408 & 0.4046 \\
0.2 & 2 & -1 & 0.4431 & 0.3954 & 0.3620 & 0.4418 & 0.3934 & 0.3590 \\
0.2 & 2 & -2 & 0.4143 & 0.3767 & 0.3487 & 0.4127 & 0.3742 & 0.3451 \\
0.2 & 2 & -3 & 0.3927 & 0.3616 & 0.3375 & 0.3906 & 0.3538 & 0.3333 \\
\hline
\end{tabular}

TABle 5: Computed values of skin friction $-f^{\prime \prime}(0)$ and local Nusselt number $-\theta^{\prime}(0)$ for different values of $r_{0}$ when $\operatorname{Pr}=0.72, n=0.5, \mathrm{M}=0.0, \beta=0.1$, and $\delta=-1$.

\begin{tabular}{ccccccc}
\hline & \multicolumn{3}{c}{$-f^{\prime \prime}(0)$} & & \multicolumn{3}{c}{$-\theta^{\prime}(0)$} \\
& $\gamma=1$ & $\gamma=2$ & $\gamma=3$ & $\gamma=1$ & $\gamma=2$ & $\gamma=3$ \\
\hline 0.0 & 0.3162 & 0.2351 & 0.1873 & 0.3211 & 0.2912 & 0.2703 \\
0.2 & 0.3161 & 0.2350 & 0.1872 & 0.3217 & 0.2917 & 0.2707 \\
0.5 & 0.3160 & 0.2349 & 0.1871 & 0.3224 & 0.2922 & 0.2717 \\
1.0 & 0.3158 & 0.2347 & 0.1870 & 0.3230 & 0.2928 & 0.2727 \\
1.5 & 0.3157 & 0.2346 & 0.1869 & 0.3237 & 0.2934 & 0.2730 \\
2.0 & 0.3156 & 0.2345 & 0.1868 & 0.3239 & 0.2935 & 0.2731 \\
\hline
\end{tabular}




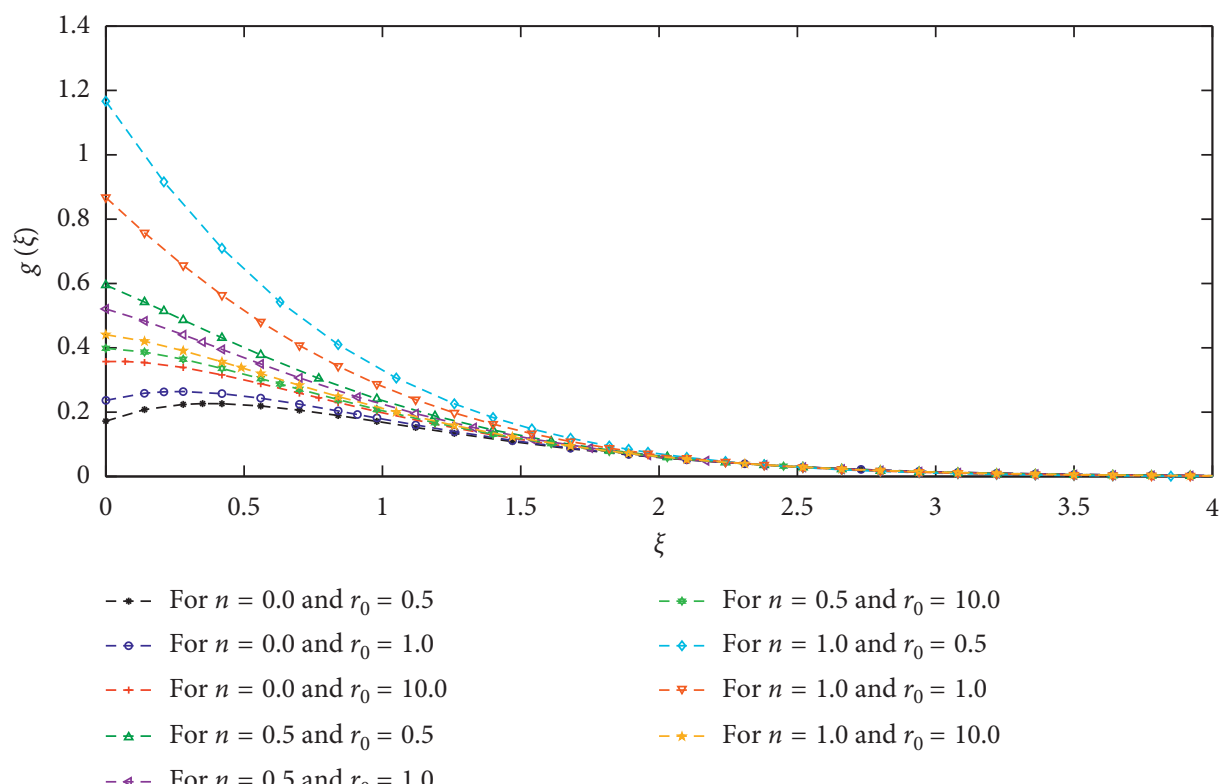

Figure 1: Impact of $n$ and $r_{0}$ on $g(\xi)$ when $M=10, \gamma=\delta=R=0$, andPr $=\beta=5$.

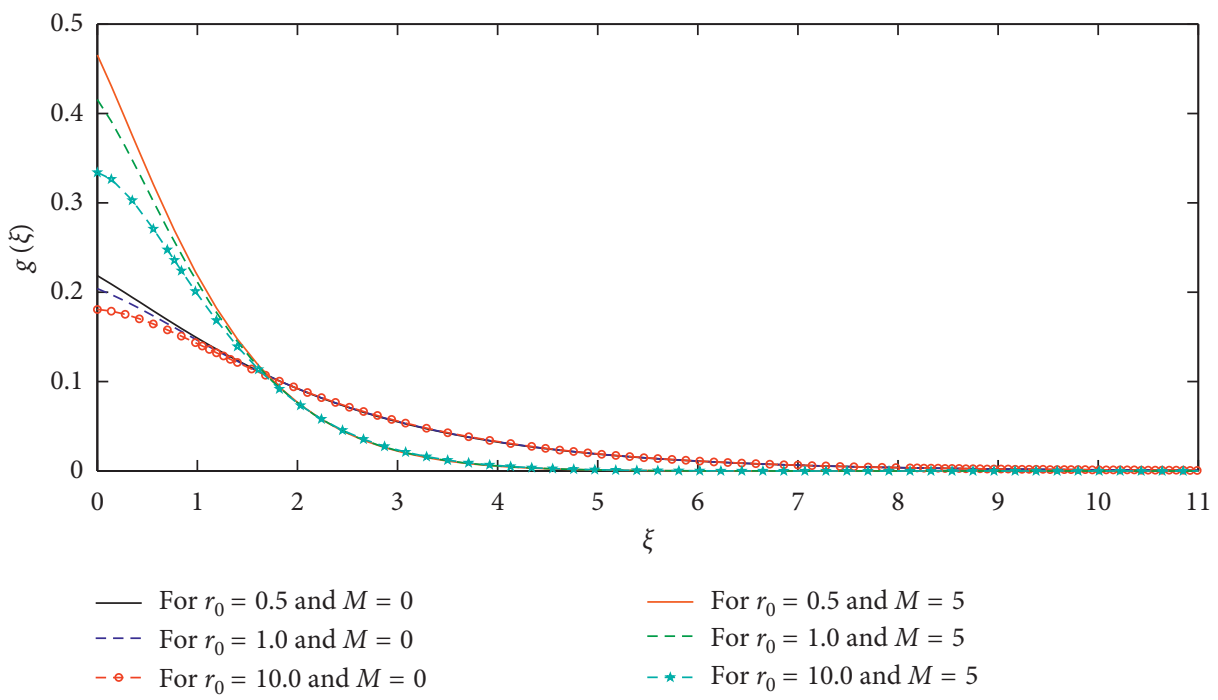

Figure 2: Impact of $M$ and $r_{0}$ on $g(\xi)$ when $n=0.5, \gamma=\delta=r_{1}=R=0$, andPr $=\beta=5$.

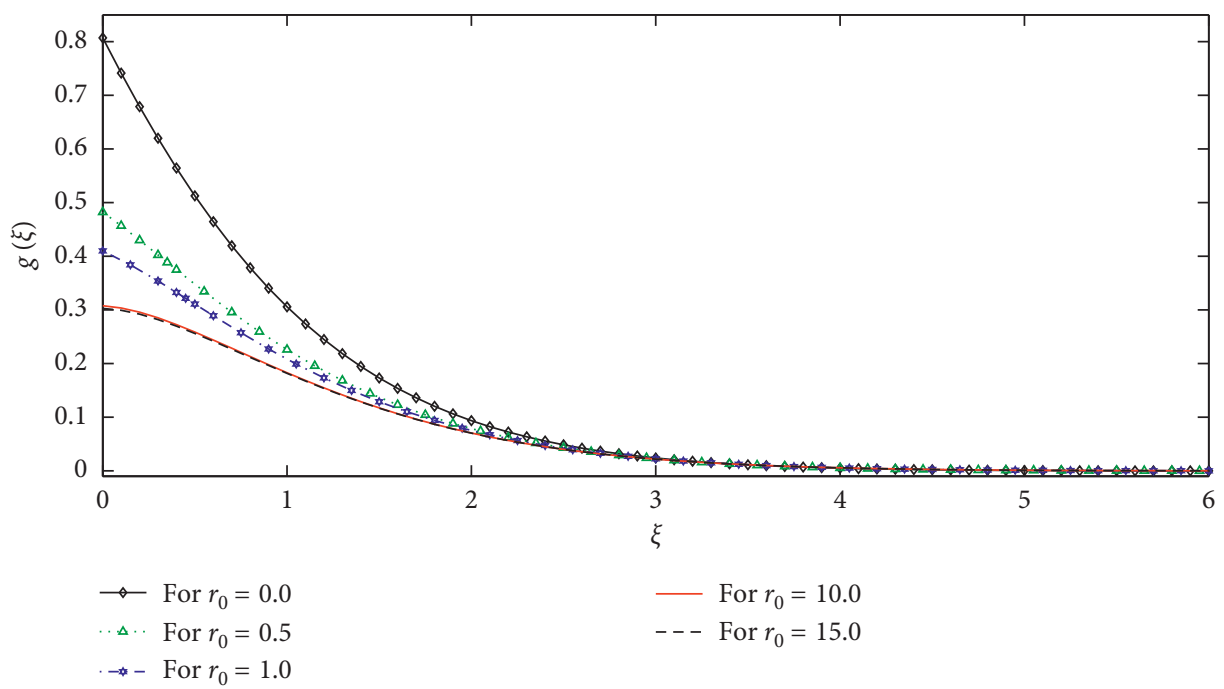

FIgURE 3: Impact of $r_{0}$ on $g(\xi)$ when $n=0.5, \gamma=\delta=1, r_{1}=R=0$, andPr $=\beta=5$. 


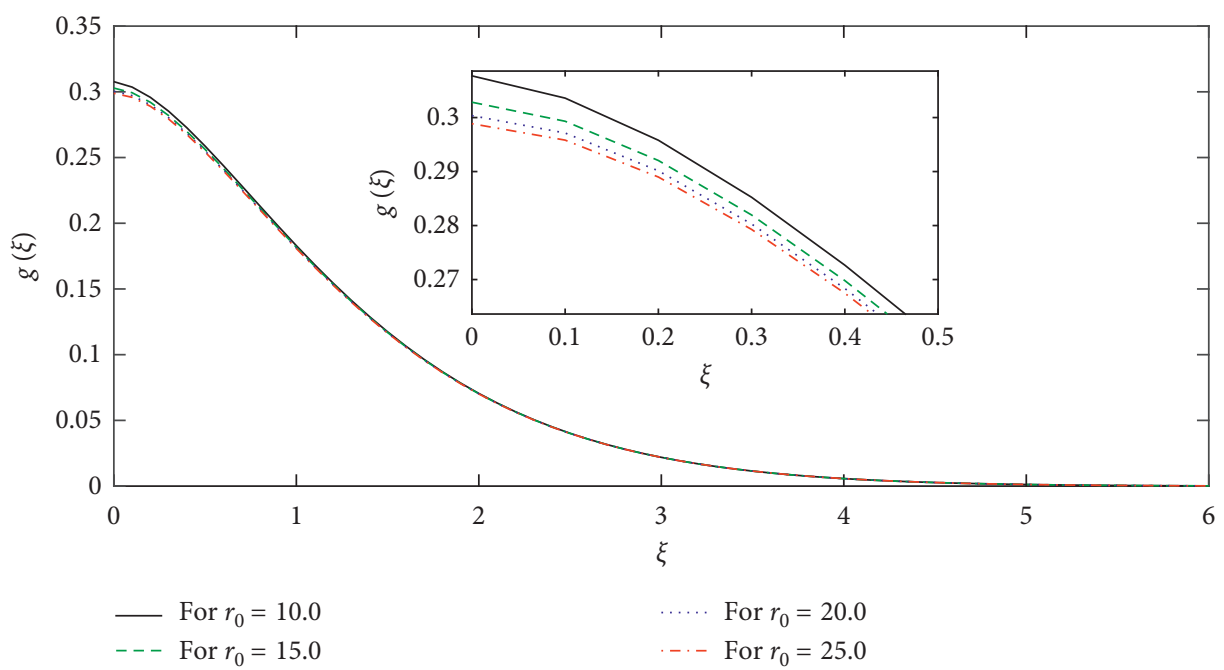

Figure 4: Impact of $r_{0}$ on $g(\xi)$ when $M=5, n=0.5, \gamma=\delta=1, r_{1}=R=0$, andPr $=\beta=5$.

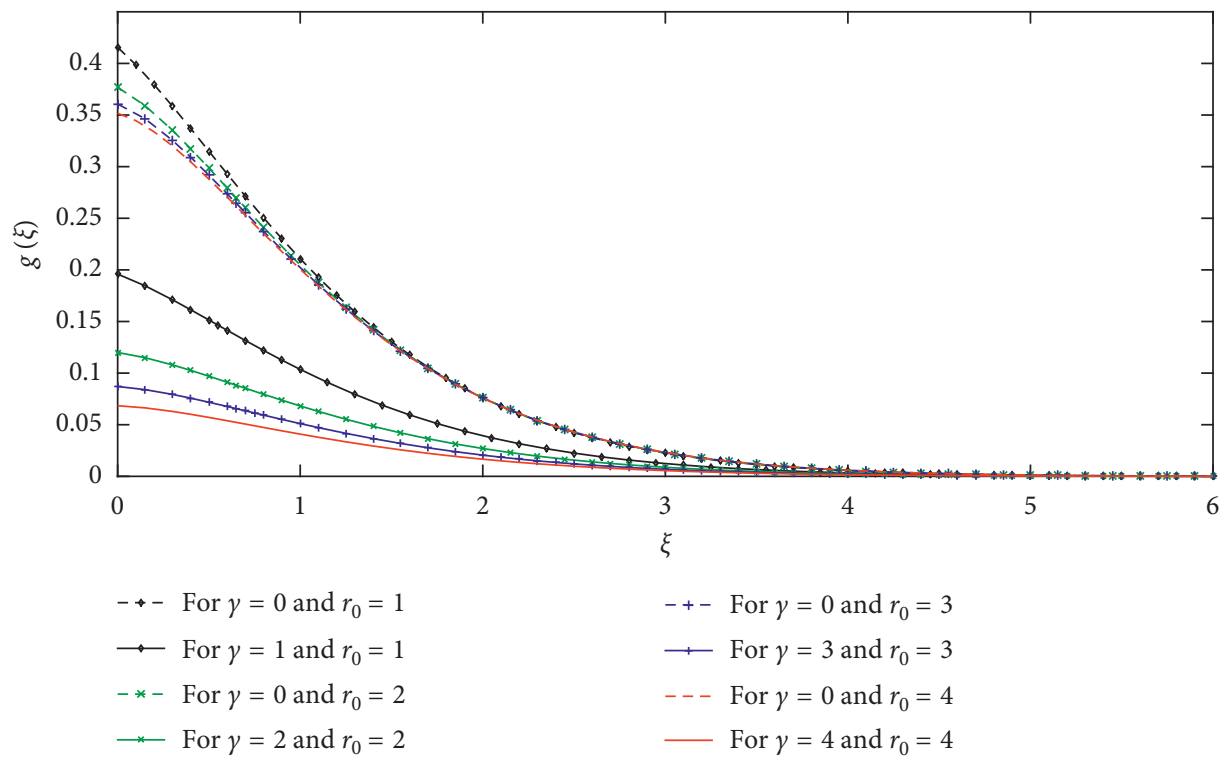

Figure 5: Impact of $\gamma$ and $r_{0}$ on $g(\xi)$ when $M=5, n=0.5, \delta=1, r_{1}=R=0$, andPr $=\beta=5$.

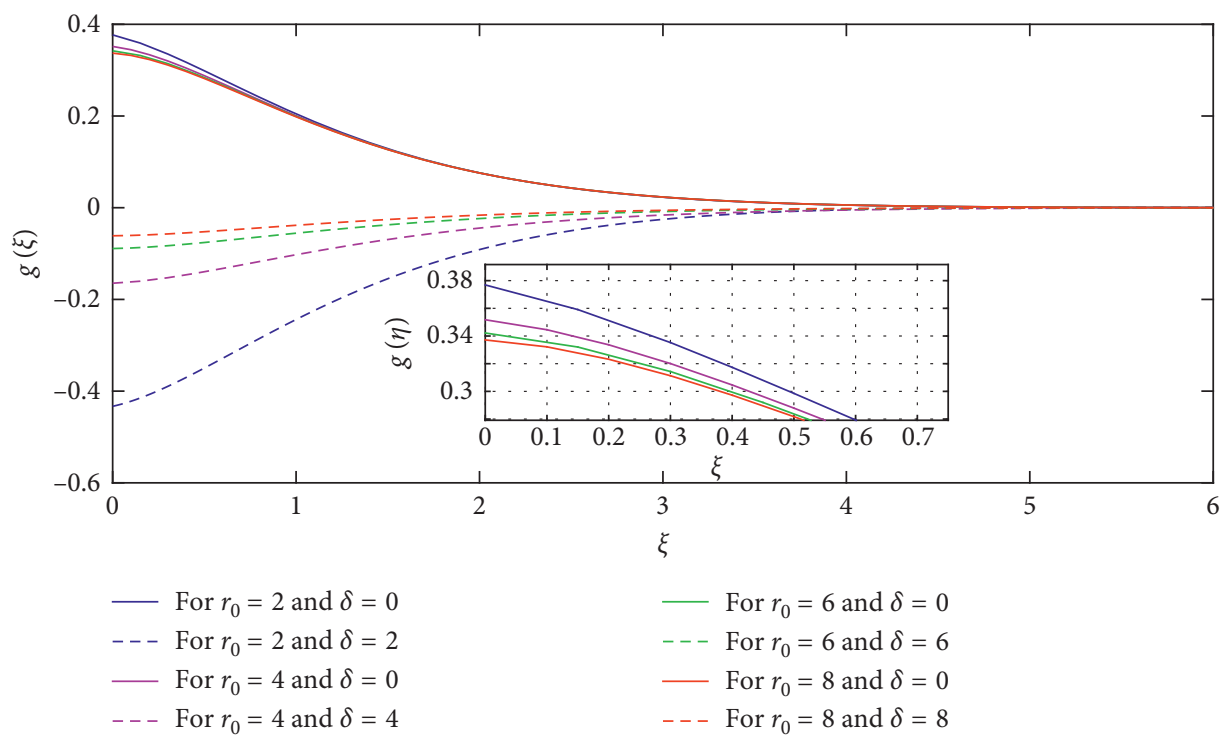

FIgURE 6: Impact of $\delta$ and $r_{0}$ on $g(\xi)$ when $M=5, n=0.5, \gamma=1, r_{1}=R=0$, andPr $=\beta=5$. 


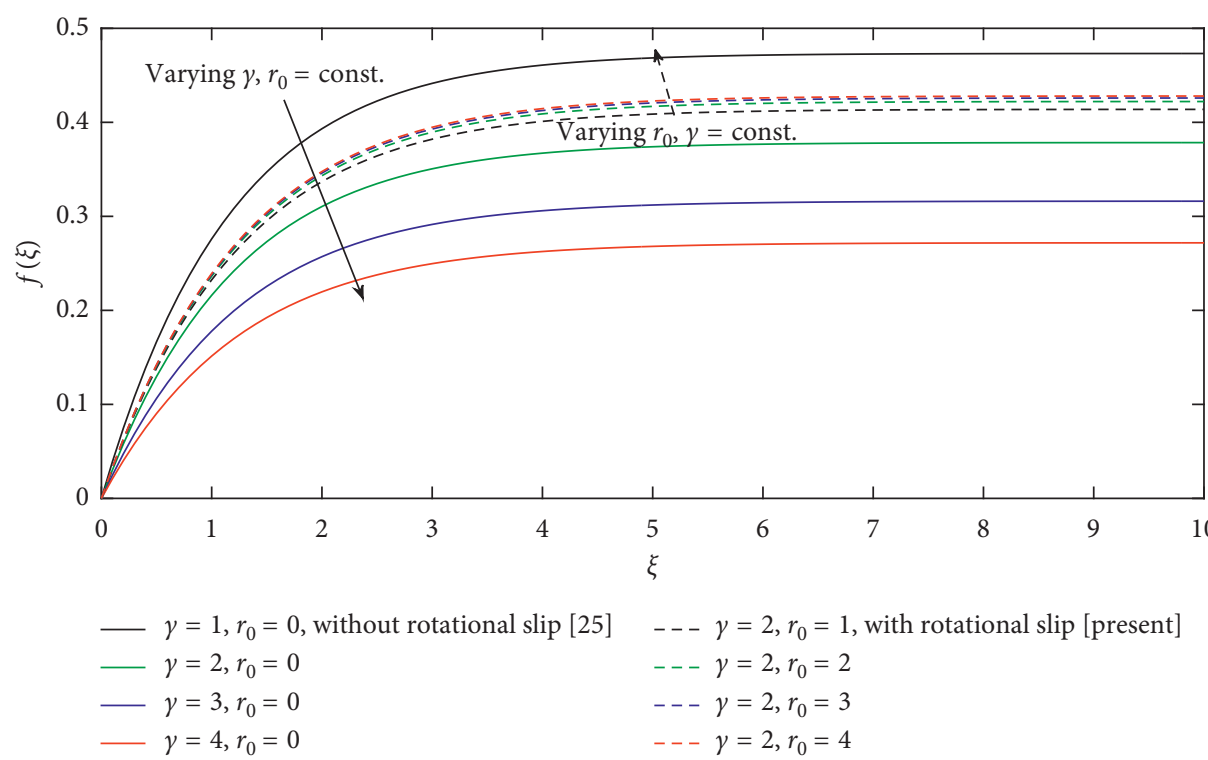

Figure 7: Impact of $\gamma$ and $r_{0}$ on $f^{\prime}(\xi)$ when $M=5, n=0.5, \delta=1, r_{1}=R=0$, andPr $=\beta=5$.

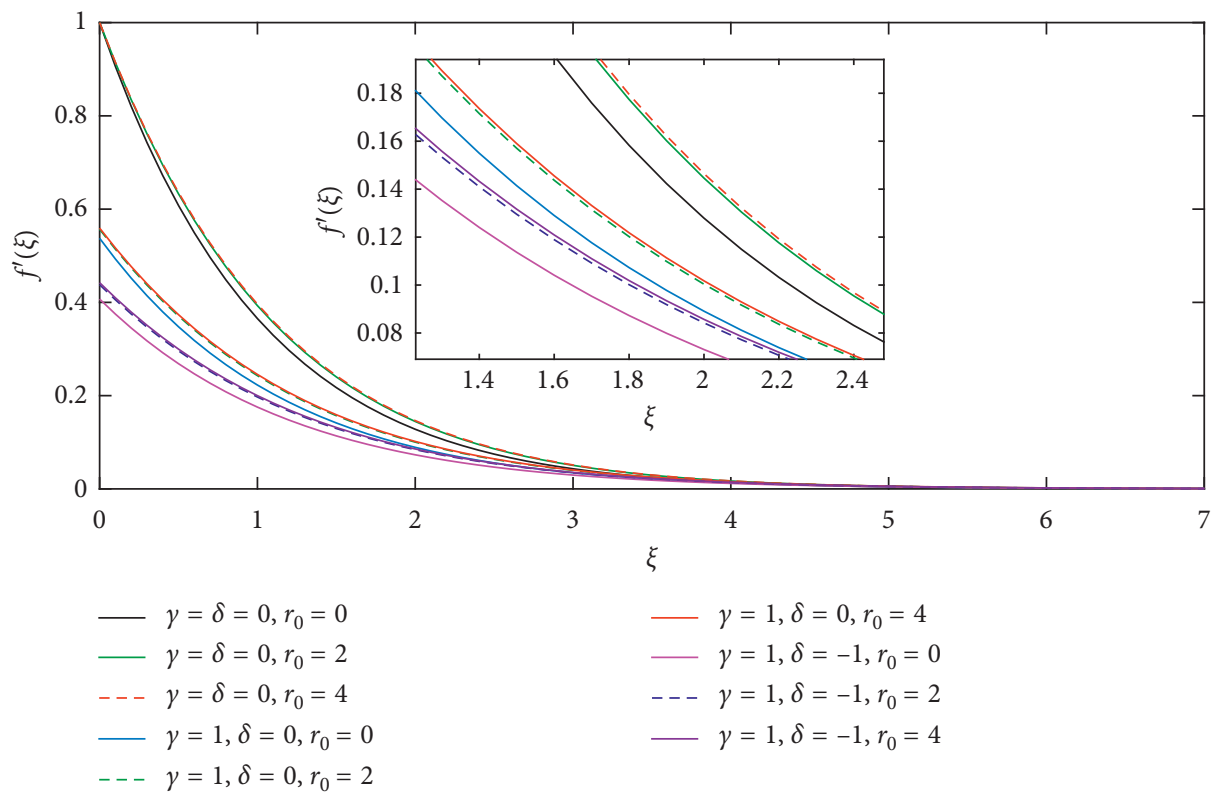

FIGURE 8: Impact of $\delta=\gamma$ and $r_{0}$ on $f^{\prime}(\xi)$ when $M=5, n=0.5, r_{1}=R=0$, and $\operatorname{Pr}=\beta=5$.

In Figure 5, the combined effect of second-order translational slip and microstructural slip on the development of microrotational velocity boundary layer is shown. It is observed that the microrotational velocity boundary layer profile in case of combined effect of microstructural slip and second-order translational slip is always lower than the case where there is only microstructural slip and no second-order translational slip. Moreover, it is observed that the variation in the thickness of microrotational velocity boundary layer in case of second-order translational slip and microstructural slip is larger than the case where only microstructural slip is present, thereby implying that the second-order translational slip do affect the microrotational boundary layer profile. By increasing the second-order translational slip parameter, the thickness of microrotational velocity boundary layer profile decreases.

In Figure 6, the combined effect of first-order translational slip and microstructural slip can be seen, where it is observed that, in the presence of first-order translational slip, the microrotations have shown a counterrotational phenomenon in comparison to the case where there is only microstructural slip effect and no translational slip effect. The variation of the thickness of boundary layer profiles is always larger in case of combined effect of translational and 


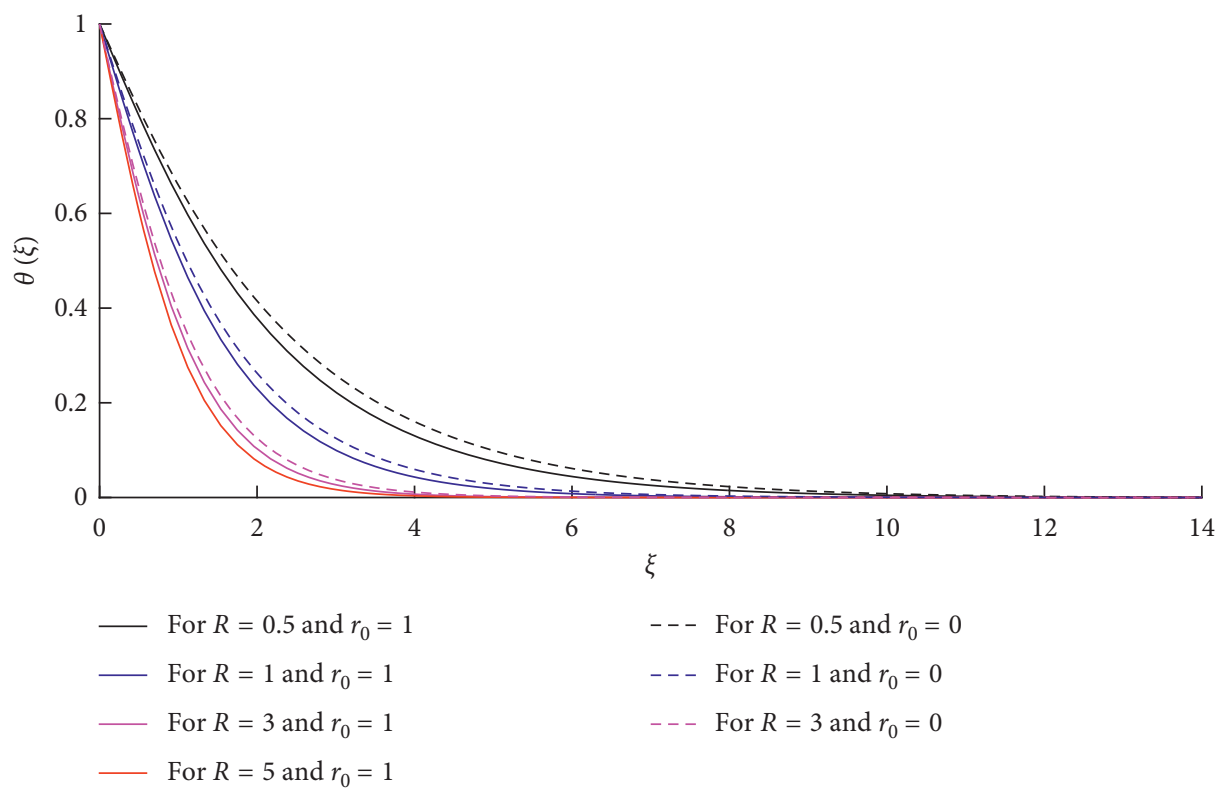

Figure 9: Impact of $R$ and $r_{0}$ on $\theta(\xi)$ when $M=\operatorname{Pr}=\beta=5, n=0.5$, and $\delta=1$.

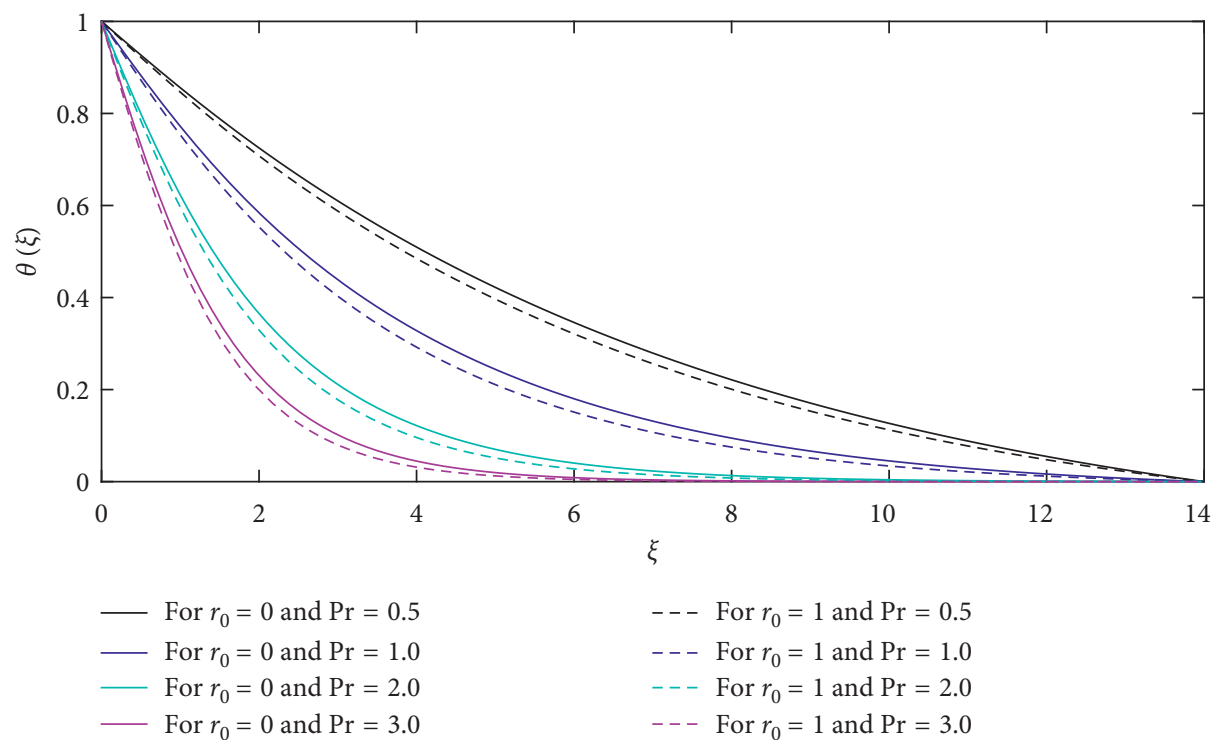

Figure 10: Impact of $\operatorname{Pr}$ and $r_{0}$ on $\theta(\xi)$ when $M=\beta=5, n=0.5, \delta=r_{1}=0$, and $\gamma=1$.

microrotational slip in comparison to the case where is no translational slip, as can be seen in Figures 5 and 6. However, in the absence of first-order translational slip, the counterrotational phenomenon near the stretching surface is not observed.

Figure 7 is plotted to notice the impact of fluid velocity in the absence and presence of microstructural slip. It is depicted that velocity profile decreases for mounting values of $\gamma$ and increases for mounting values of slip parameter $r_{0}$

Figure 8 shows the combined influence of $f^{\prime}(\eta)$ on growing values of slip parameter and fixed values of $\gamma$ and $\delta$. It is analyzed that the velocity profile increases. Figure 9 is plotted to notice the behavior of temperature profile for varying values of radiation parameter in the presence and absence of microstructural slip. It is observed that fluid temperature decreases for growing values of radiation parameter in both the cases. Figure 10 shows the impact of Prandtl number on fluid temperature in the absence and presence of microstructural slip, and it is observed that fluid temperature decreases for higher values of Prandtl number in both the cases. In Figure 11, the impact of magnetic parameter $M$ on temperature profile is observed in the absence and presence of microstructural slip. The fluid temperature increases for an increasing value of magnetic parameter. Figure 12 indicates the impact of material parameter $\beta$ in the absence and presence of microstructural slip. The decline in fluid temperature is noticed. 


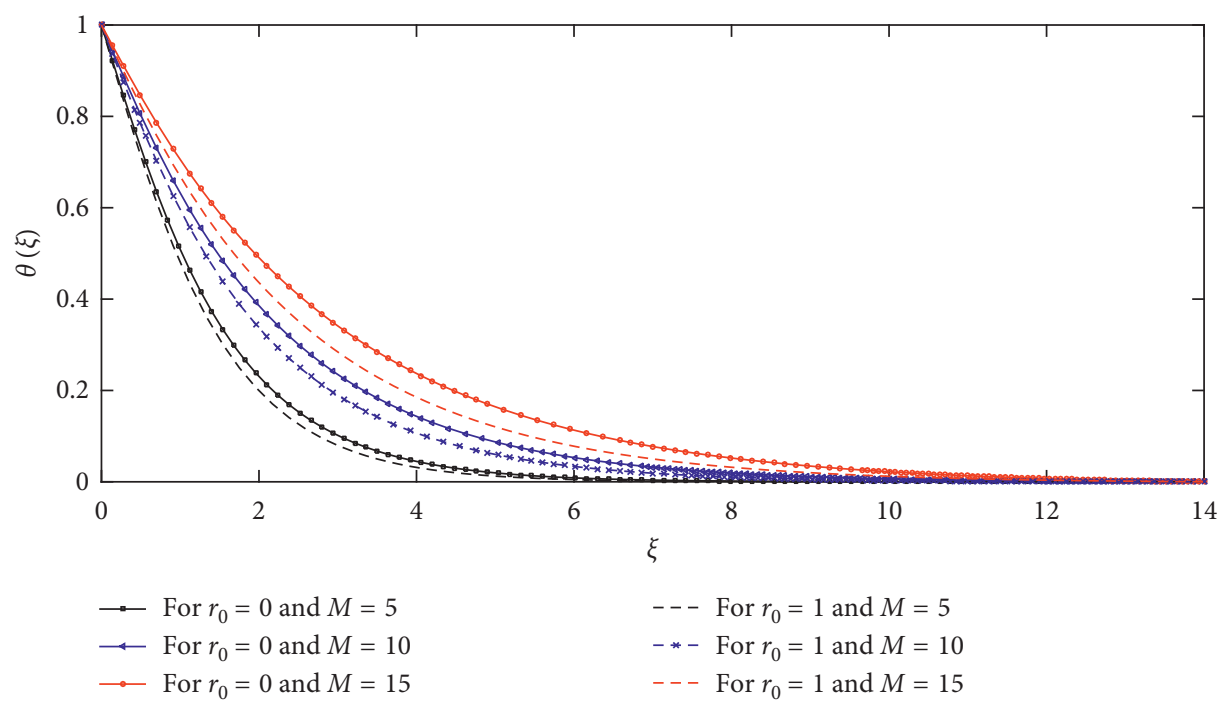

Figure 11: Impact of $M$ and $r_{0}$ on $\theta(\xi)$ when $\operatorname{Pr}=3, \beta=R=5, n=0.5$, and $\delta=r_{1}=0$.

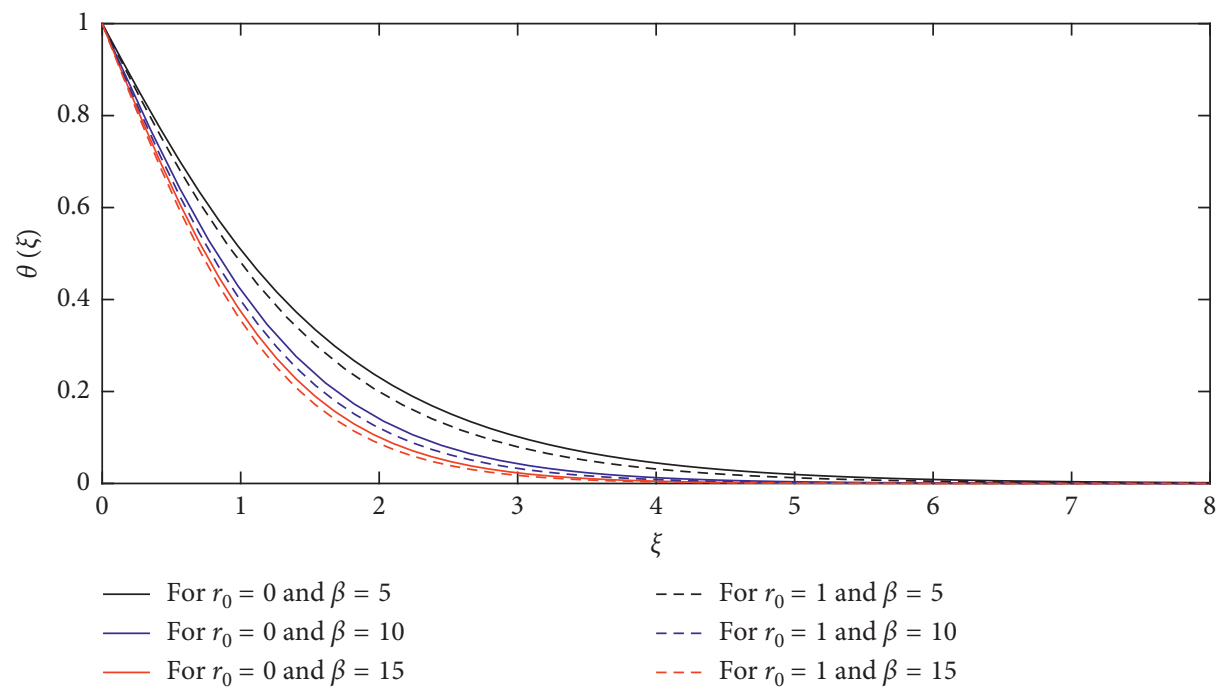

FIgURe 12: Impact of $\beta$ and $r_{0}$ on $\theta(\xi)$ when $M=R=5, \operatorname{Pr}=3, n=0.5, \delta=r_{1}=0$, and $\gamma=1$.

\section{Conclusion}

The aim of this paper is to investigate the effects of microstructural slip on the development of hydrodynamic and thermal boundary layers. Moreover, its effect on the skin friction coefficient and Nusselt number of a micropolar flow governed by a set of PDEs along with initial-boundary conditions is studied. The resulting equations are solved numerically using the bvp4c scheme. The main findings of this study can be summarized as follows:

(i) Microrotational boundary layer thickness decreases in both the cases with increase in microstructural slip

(ii) In the presence of microstructural slip, the microrotational velocity boundary layer thickness decreases up to a maximum of $37.5 \%$ in its value, in comparison to the case where there is no microstructural slip effect

(iii) Increasing the second-order translational slip parameter, the thickness of microrotational velocity boundary layer profile decreases

(iv) In the presence of first-order translational slip, the microrotations have shown a counterrotational phenomenon in comparison to the case where there is only microstructural slip effect and no translational slip effect

(v) In the absence of first-order translational slip, the counterrotational phenomenon near the stretching surface is not observed

(vi) Increasing the values of microstructural slip parameter and magnetic parameter reduces the fluid velocity 
(vii) Increasing the values of Prandtl number and radiation parameter decreases the fluid temperature in the absence as well as in the presence of microstructural slip

(viii) Decrease in temperature profile thickness is noticed for growing values of microstructural slip parameter

\section{Abbreviations}

$\begin{array}{ll}A: & \text { Stretching constant } \\ A \text { and } B: & \text { Slip constants } \\ B_{0}: & \text { Magnetic field strength } \\ K: & \text { Thermal conductivity of fluid } \\ C_{f}: & \text { Skin friction coefficient } \\ k: & \text { Coefficient of vortex viscosity } \\ f: & \text { Dimensionless stream function } \\ g: & \text { Dimensionless microrotation function } \\ j: & \text { Microinertia density } \\ K n: & \text { Knudsen number } \\ \Psi: & \text { Stream function } \\ M: & \text { Magnetic parameter } \\ n: & \text { Microrotation parameter } \\ \text { Nux: } & \text { Local Nusselt number } \\ \tau \mathrm{w}: & \text { Wall shear stress } \\ \text { Pr: } & \text { Prandtl number } \\ \mathrm{Qw}: & \text { Surface heat flux } \\ \text { Rex: } & \text { Local Reynolds number } \\ \alpha: & \text { Momentum accommodation coefficient } \\ \gamma: & \text { First-order slip parameter } \\ \delta: & \text { Second-order slip parameter } \\ \eta: & \text { Dimensionless similarity variable } \\ N: & \text { Microrotation component normal to xy plane } \\ C p: & \text { Specific heat } \\ M: & \text { Coefficient of dynamic viscosity } \\ v: & \text { Coefficient kinematic viscosity } \\ \sigma: & \text { Electrical conductivity } \\ \lambda: & \text { The molecular mean free path } \\ \Lambda: & \text { Thermal diffusivity } \\ \beta: & \text { Material parameter } \\ \rho: & \text { Fluid density } \\ \Omega: & \text { Coin-gradient viscosity } \\ \infty: & \text { Condition at the free stream } \\ w: & \end{array}$

\section{Data Availability}

Data used to support the findings of this study are available from the corresponding author upon request.

\section{Conflicts of Interest}

The authors declare that they have no conflicts of interest.

\section{Acknowledgments}

This research was supported by the National Natural Science Foundation of China (No. 71601072) and Key Scientific
Research Project of Higher Education Institutions in Henan Province of China (No. 20B110006).

\section{References}

[1] C. Neto, D. R. Evans, E. Bonaccurso, H.-J. Butt, and V. S. J. Craig, "Boundary slip in Newtonian liquids: A review of experimental studies," Reports on Progress in Physics, vol. 68, no. 12, pp. 2859-2897, 2005.

[2] R. Ellahi, "Exact solutions of flows of an oldroyd 8-constant fluid with nonlinear slip conditions," Zeitschrift für Naturforschung A, vol. 65, no. 12, pp. 1081-1086, 2010.

[3] A. Hussain, S. T. Mohyud-din, and T. A. Cheema, "Analytical and numerical approaches to squeezing flow and heat transfer between two parallel disks with velocity slip and temperature jump," Chinese Physics Letters, vol. 29, no. 11, Article ID 114705, 2012.

[4] A. Cemal Eringen and P. R. Paslay, "Nonlinear theory of continuous media," Journal of Applied Mechanics, vol. 31, no. 2, p. 368, 1964.

[5] A. Eringen, "Theory of micropolar fluids," Indiana University Mathematics Journal, vol. 16, no. 1, pp. 1-18, 1966.

[6] M. S. Khan, M. Hammad, S. Batool, and H. Kaneez, "Investigation of MHD effects and heat transfer for the upperconvected Maxwell (UCM-M) micropolar fluid with joule heating and thermal radiation using a hyperbolic heat flux equation," The European Physical Journal Plus, vol. 132, no. 4, 2017.

[7] I. Abdullah and N. Amin, "A micropolar fluid model of blood flow through a tapered artery with a stenosis," Mathematical Methods in the Applied Sciences, vol. 33, no. 16, pp. 1910-1923, 2010.

[8] G. Bayada and G. Łkaszewicz, "On micropolar fluids in the theory of lubrication. Rigorous derivation of an analogue of the Reynolds equation," International Journal of Engineering Science, vol. 34, no. 13, pp. 1477-1490, 1996.

[9] L. J. Crane, "Flow past a stretching plate," Zeitschrift für angewandte Mathematik und Physik ZAMP, vol. 21, no. 4, pp. 645-647, 1970.

[10] P. S. Gupta and A. S. Gupta, "Heat and mass transfer on a stretching sheet with suction or blowing," The Canadian Journal of Chemical Engineering, vol. 55, no. 6, pp. 744-746, 1977.

[11] X. He and C. Cai, "Near continuum velocity and temperature coupled compressible boundary layer flow over a flat plate," Brazilian Journal of Physics, vol. 47, no. 2, pp. 182-188, 2017.

[12] S. Xinhui, L. Haozhe, Y. Shen, and L. Zheng, "Effects of nonlinear velocity slip and temperature jump on pseudoplastic power-law fluid over moving permeable surface in presence of magnetic field," Applied Mathematics and Mechanics, vol. 38, no. 3, pp. 333-342, 2017.

[13] E. Hosseini, G. B. Loghmani, M. Heydari, and M. M. Rashidi, "Numerical investigation of velocity slip and temperature jump effects on unsteady flow over a stretching permeable surface," The European Physical Journal Plus, vol. 132, no. 2, p. 96, 2017.

[14] M. Farhan, Z. Omar, F. Mebarek-Oudina et al., "Implementation of one step one hybrid block method on nonlinear equation of the circular sector oscillator," Computational Mathematics and Modeling, vol. 31, no. 1, pp. 116-132, 2020.

[15] Y. S. Daniel, Z. A. Aziz, Z. Ismail, and F. Salah, "Effects of slip and convective conditions on MHD flow of nanofluid over a porous nonlinear stretching/shrinking sheet," Australian Journal of Mechanical Engineering, vol. 16, no. 3, pp. 213-229, 2017. 
[16] F. Mebarek-Oudina, A. Aissa, B. Mahanthesh, and H. F. Öztop, "Heat transport of magnetized Newtonian nanoliquids in an annular space between porous vertical cylinders with discrete heat source," International Communications in Heat and Mass Transfer, vol. 117, Article ID 104737, 2020.

[17] M. Mahmoud and S. Waheed, "Effects of slip and heat generation/absorption on MHD mixed convection flow of micropolar fluid over a heated stretching surface," Mathematical Problems in Engineering, vol. 2010, pp. 1-20, Article ID 579162, 2010.

[18] A. Mahmood, M. Basir, U. Ali, M. Kasihmuddin, and M. Mansor, "Numerical solutions of heat transfer for magnetohydrodynamic jeffery-hamel flow using spectral Homotopy analysis method," processes, vol. 7, no. 9, p. 626, 2019.

[19] S. Mukhopadhyay, "Slip effects on MHD boundary layer flow over an exponentially stretching sheet with suction/blowing and thermal radiation," Ain Shams Engineering Journal, vol. 4, no. 3, pp. 485-491, 2013.

[20] U. Ali, F. A. Abdullah, and S. T. Mohyud-Din, "Modified implicit fractional difference scheme for 2D modified anomalous fractional sub-diffusion equation," Advances in Difference Equations, vol. 2017, no. 1, pp. 1-14, 2017.

[21] M. Sohail, U. Ali, Q. Al-Mdallal et al., "Theoretical and numerical investigation of entropy for the variable thermophysical characteristics of couple stress material: Applications to optimization," Alexandria Engineering Journal, 2020.

[22] U. Ali, M. Sohail, and F. A. Abdullah, "An efficient numerical scheme for variable-order fractional sub-diffusion equation,", Symmetry, vol. 12, no. 9, p. 1437, 2020.

[23] U. Ali and F. A. Abdullah, "Modified implicit difference method for one-dimensional fractional wave equation," AIP Conference Proceedings, vol. 2018, Article ID 060021, 2019.

[24] U. Ali, M. Sohail, M. Usman, F. A. Abdullah, I. Khan, and K. S. Nisar, "Fourth-order difference approximation for timefractional modified sub- diffusion equation," Symmetry, vol. 12 , no. 5 , p. $691,2020$.

[25] S. I. Abdelsalam and M. Sohail, "Numerical approach of variable thermophysical features of dissipated viscous nanofluid comprising gyrotactic micro-organisms," Pramana, vol. 94, no. 1, 2020.

[26] M. M. A. Khater, D. Lu, and R. A. M. Attia, “Dispersive long wave of nonlinear fractional $\mathrm{Wu}$-Zhang system via a modified auxiliary equation method," AIP Advances, vol. 9, no. 2, Article ID 025003, 2019.

[27] H. Rezazadeh, A. Korkmaz, M. M. Khater, M. Eslami, D. Lu, and R. A. M. Attia, "New exact traveling wave solutions of biological population model via the extended rational sinhcosh method and the modified Khater method," Modern Physics Letters B, vol. 33, no. 28, Article ID 1950338, 2019.

[28] R. Attia, D. Lu, and M. M. A. Khater, "Chaos and relativistic energy-momentum of the nonlinear time fractional duffing equation," Mathematical and Computational Applications, vol. 24, no. 1, p. 10, 2019.

[29] S. Deo and P. Shukla, "Creeping flow of Micropolar fluid past a fluid sphere with non-zero spin boundary condition," International Journal of Engineering \& Technology, vol. 1, no. 2, pp. 67-76, 2012.

[30] W. Ibrahim, "MHD boundary layer flow and heat transfer of micropolar fluid past a stretching sheet with second order slip," Journal of the Brazilian Society of Mechanical Sciences and Engineering, vol. 39, no. 3, pp. 791-799, 2017.

[31] S. K. Jena and M. N. Mathur, "Similarity solutions for laminar free convection flow of a thermomicropolar fluid past a non- isothermal vertical flat plate," International Journal of Engineering Science, vol. 19, no. 11, pp. 1431-1439, 1981.

[32] G. Ahmadi, "Self-similar solution of imcompressible micropolar boundary layer flow over a semi-infinite plate," International Journal of Engineering Science, vol. 14, no. 7, pp. 639-646, 1976. 